\title{
Comparison of Self-Regulation Strategies in Elite Basketball Players Based on Personality Types
}

\author{
Mohsen Parvazi Shandi ${ }^{1,}$, Zahra Pooraghaei Ardekani², Saber Mehri ${ }^{1}$ \\ ${ }^{1}$ Sport Psychology Department, Allameh Tabataba'i University, Tehran, Iran \\ ${ }^{2}$ Motor Behaviour Department, Allame Tabataba'i University, Tehran, Iran
}

Email address:

Mohsen.p006@gmail.com (M. P. Shandi)

\section{To cite this article:}

Mohsen Parvazi Shandi, Zahra Pooraghaei Ardekani, Saber Mehri. Comparison of Self-Regulation Strategies in Elite Basketball Players Based on Personality Types. American Journal of Sports Science. Vol. 4, No. 2, 2016, pp. 18-24. doi: 10.11648/j.ajss.20160402.11

\begin{abstract}
Introduction: Nowadays, identification of factors related to success of athletes is considered as one of the important issues in psychology of sport. Self-regulation is one of these factors investigated recently. The aim of this study is to compare self-regulation strategies of Iranian basketball players based on their personality types. Method: subjects of this study were male basketball players of Iranian super league in 2013-2014, which 118 of them were selected as sample of study, based on Morgan sample size table. Miller and Brown's Self-Regulation Questionnaire and Eysenck personality were used in this study. Since the number of introverts was low, they were excluded in the present study. In addition, sample of study was divided into two groups of stable extroverts and unstable extroverts, based on Eysenck personality. Results: results indicated that there was significant difference between two groups. Results also showed that each of these groups use various strategies to self-regulation. Conclusion: considering personality types, individuals can use various strategies for self-regulation that this issue can play role in achieving their goals and successes.
\end{abstract}

Keywords: Self-Regulation, Personality Dimensions, Basketball Players, Extroverts

\section{Introduction}

The performance of athletes in sports competitions certainly depends on technical, tactical and psychological skills. Nowadays, many researchers investigate the psychological aspects and factors affecting their championship. One of the psychological factors considered recently in the sport is the source of self-regulation that has been known as effective source to achieve success among people (Magar et al 2008). Self-regulation can be defined as source in order to control, modify, and regulate emotions and desires (Toering et al., 2009).

Researchers have studied self-regulation in two parts of cognitive-regulation and emotion-regulation as a source to control feelings and emotions, while cognitive-regulation refer to control of thoughts and actions related to planned and executive behavior (Banfield et al., 2004). On the other hand, Zimmerman (1986, 1989, 2006), presented self-regulated learning theory, self-regulation, defines self-regulation as meta-cognitive, motivational, and behavioral level in which individuals participate actively in the process of training.

Self-regulation skills are significantly correlated with general adoptability, health-related habits, and athletic performance (Barkhof, Pagano and Hibi, 2007). Studies have shown that deficiency in self-regulation is an important psychological barrier to display health-related behaviors such as practice (Hagger et al., 2010). Kanfer (1970) presented a three-step model of self-regulation. 1) Self-monitoring that includes the ability to see and understand the behavior of another. 2) Self-assessment that involves comparison of that behavior with internal or external norm. 3) self-improving that focuses on any difference between two previous steps. Understanding this difference may encourage the person to make an effort to change the behavior that this would be done by the third stage. In this view, self-regulation is the ability to develop, implement and maintain a planned behavior in a flexible manner to achieve intended purpose.

One of the interesting models among those models presented by researchers in this regard is the model that has been introduced by Miller and Brown (1991). This model considers self-regulation as a seven-step process and it emphasizes that deficiency in each of these steps leads into disorder in behavioral regulation. In addition, this creative model presents proper interventions considering some special deficiencies in each of these steps. These steps include: 1) 
receive relevant information, 2) Evaluation of the information and comparing it with norms 3) trigger changes 4) search of options 5) formulate a map 6) implement the plan 7) assess the plan's effectiveness.

In the first step, this model refer to provide information on situations that lead to learning that environmental related information should be given based on the goal. In the second step, by allowing people to think through different decisionmaking, it claims that this process is a vital principle to development of individuals that should be trained by coaches. The third step of the process refers to the first two steps should trigger the action that must be done in the next step by issuing the command of movement or war slogan. In the next step, this model states that there are several ways to achieve individual goal and this depends on preferences and styles of each of individuals.

The fifth step suggests that map of people should be simple and accessible and look that where that person is located. The sixth step of the process is the most difficult step because it depends on this issue that how map is regulated and implemented. Finally, the seventh step is to assess the effectiveness of the map that reconstruct the first two steps and follows it if it is evaluated positively (Kanfer, 1970). The model also shows that people with low self-regulation has little ability to regulate goals consistent with the norms (eg, sport laws) and progress in order to achieve those goals. This group of people prefers immediate satisfaction rather than achieving long-term goals (Neal \& Carey, 2005).

On the other hand, in addition to self-regulation skills, studying the personality traits is another area of interest in the field of psychological research (Hoyt et al., 2009), and we compared self-regulation strategies based on personality types. Assessing personality and describing personality traits have been interested by psychologists since long times ago. In the current era, identifying personality traits in many life situations is necessary.

There are various theories in the area of personality, such as social learning theory, psychoanalytic theory and the theory of personality traits. Allport (1937) defined the personality as follows: "personality is a dynamic organization of mental-physical systems within an individual that determine his behaviors and thoughts." Lazarus and Monat (1979) define personality as relatively stable psychological processes and structures that organize human experience and shape actions and reactions of the person to the environment. Eysenck (1947 and 1975) defined personality as an integrated whole of disposition, temperament, intelligence and body. He believed that simplest responses are at the simplest level. Some of these responses are usually linked to each other and create habits. Some of these habits are associated with each other and form traits. Eysenck claimed that two important and prominent dimensions of extraversion-introversion and neuroticism are more effective than other factors and he believed that by combining these two dimensions, people are divided into four personality types: stable introvert, unstable introvert, stable extrovert, and unstable extrovert. Introverts are controlled by central nervous system, they have high natural talent to be stimulated, and they control their emotions well and they try to avoid from stimuli, changes and many social activities. They are quiet, reserved, cautious, reliable and non-aggressive and they give great value to ethical norms (Dadsetan, 2004; Feist and Feist, 2004). In contrast, extroverts have low talent to be stimulated and they are under central nervous system. Eysenck define these groups of people with some features such as society demanding, excitement, arousal, optimism and need to stimulus and change environment. Extraverts are frequently experiencing mood and aggression changes. They also enjoy being together and participation in parties (Dadsetan, 2004).

Skills (in addition to factors such as ability and motivation) partly refer to functional differences in athletes when they face with difficult situations such as high-level competitions. These skills may help athletes to set championship goals in the competitive setting and finding them in the competition conditions. Therefore, selfregulation skills are considered as extension of athletes' performance from low-level conditions to hard level competition. In addition, these skills may control some factors such as the level of arousal and performance prediction and that increase athletic performance (Zimmerman, 1999). Stadler, Oettingen and Gollwitzer (2009) conducted a study on two groups of women that one of the groups was given instructions to learn self-regulation skills. The results showed that women who had been trained in self-regulation skills were more active and more obedient than the control group. In a study conducted by Toering et al (2009), results showed that high scores on the thought and effort were related with better performance, as components of self-regulation.

Based on literature of research in this field and the importance of self-regulation skills in the sport as well as the effects that these skills can have in basketball as a field that is constantly fluctuating emotions, we decided to compare elf-regulatory skills of basketball players of Iranian super league based on their personality types.

\section{Methodology}

\subsection{Participants}

Subjects of this research included basketball players played in the 2013-2014 season of Iranian super league, which 118 of them (with average age of $22.9 \pm 3.2$ and playing experience of $9.6 \pm 4.04$ year) were randomly selected as sample of study, based on Morgan sample size table.

\subsection{Instrumentation}

\subsubsection{Miller and Brown Self-Regulation Questionnaire (SRQ)}

In order to assess the components of the self-regulation, Miller and Brown self-regulation questionnaire was used. This questionnaire includes 63 items and 7 subscales (receiving relevant information, evaluation of the 
information and comparing it with norms, trigger changes, search for options, formulate a map, implementing the plan, and assessing the plan's effectiveness, which is made by Miller and Brown in 1999. The test retest reliability of test was reported high $(r=0.94, p<0.0001)$. In addition, this test had high internal consistency $(\mathrm{a}=0.91)$ (Brown et al 1999). In Iran, this scale was validated by Dehghani (1390), and its test-retest reliability was reported 0.94 and its internal consistency was reported 0.91 .

This scale is scored from 1 to 5 in the form of Likert grading. In this scale, a score above 239 indicates high selfregulation, score between 239-214 indicates middle selfregulation, and a score below 213 indicates low selfregulation.

\subsubsection{Eysenck Personality Questionnaire}

Eysenck Personality questionnaire is a self-assessment of personality questionnaire measures the personality in three fundamental dimensions. These three dimensions include introversion-extraversion, neuroticism and psychoticism. However, shortened form of this scale was used which assess dimensions of introversion-extraversion and neuroticism (emotional stability-instability) and tendency to lying by 57 items. In the scoring of this questionnaire, no answer receives score of zero, while yes response receives score of one.

This questionnaire was firstly developed by Eysenck and Eysenck (EPQ,1975), then it was reviewed by Eysenck et al (EPQ-R,1985) and found its reliability, internal consistency (Cronbach's alpha coefficient) scales of extroversion, neuroticism, and lying as $0.90,0.88$ and 0.82 in men, and $0.85,0.85$ and 0.79 in women, respectively. In Iran, the questionnaire has been validated several times that in one them Rafee Nia (2006) found these coefficients as $0.76,0.84$ and 0.67 , respectively.

\subsection{Implementation}

Explanation provided to the participants. Therefore, they were asked to respond the short form of Eysenck Personality Inventory (EPQ) and Miller and Brown self-regulation quest (SRQ). Since data collection, because of the multitude of extroverts $(83 / 89 \%)$ and the small number of introverts sample $(17 / 10 \%)$, the introvert athletes were excluded. Based on classification of personality types of Eysenck, subjects were divided into unstable extroverts (60 persons) and stable extroverts (46 persons). SPSS 20 software was used to analyze data of study. In order to investigate the difference between two groups of stable extroverts and unstable extroverts, t-test was used to two independent groups, after investigating the normal distribution of data by using Kolmogorov-Smirnov test and determining the homogeneity of variances by using Lone statistics. In addition, the effect size was calculated for each of the tests.

\section{Results}

Figure 1 shows the mean scores of elf-regulation strategies in two groups of stable extroverts and unstable extroverts. As can be seen, in majority of the self-regulation strategies the stable extrovert group has relative advantage. The total score of the self-regulation in the stable extrovert group is higher than unstable group. Only in the evaluation strategy, no significant difference was found.

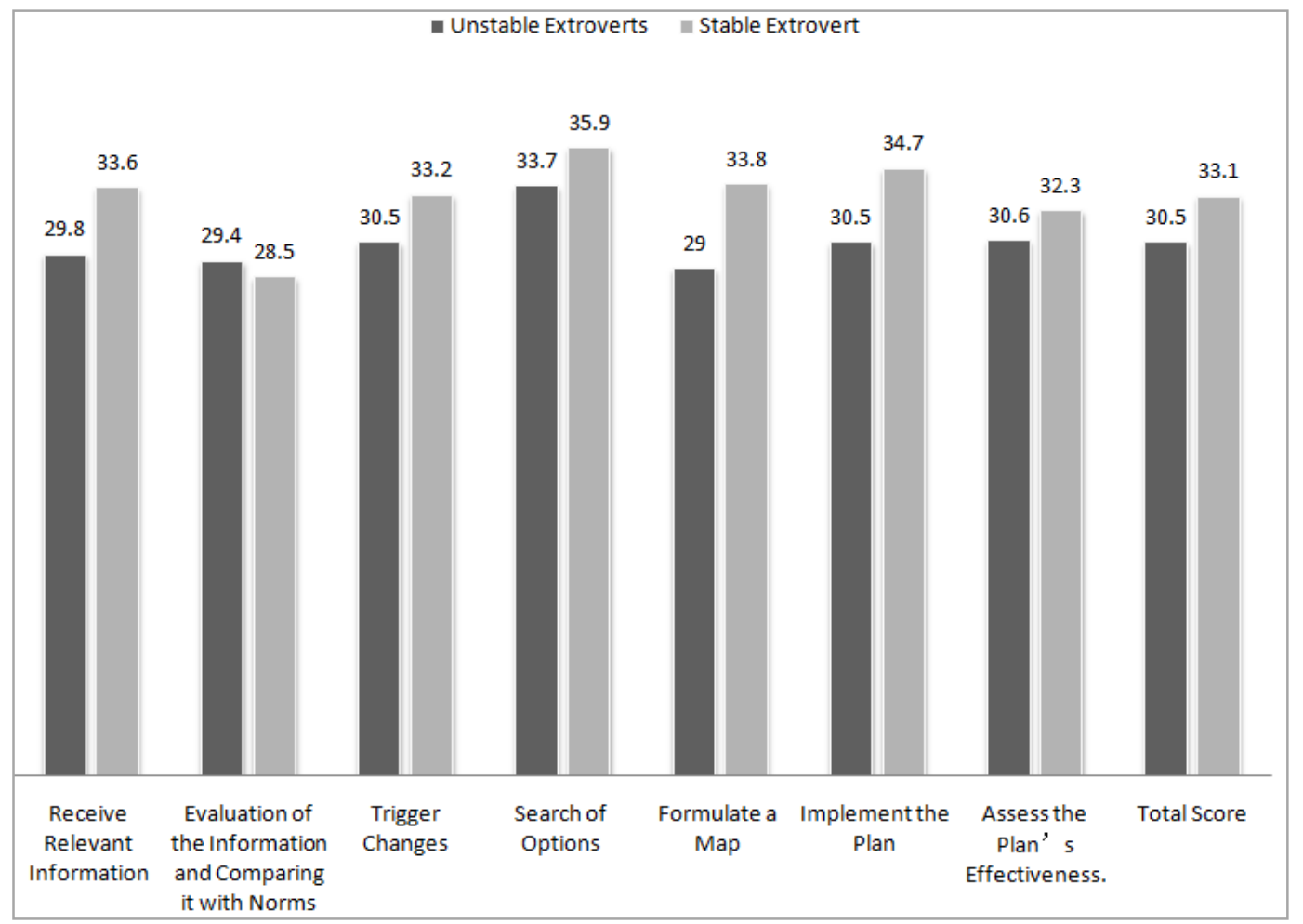

Figure 1. Comparison of self-regulation mean scores'strategies of athletes who have stable and unstable extrovert personality. 
Table 1. Self-regulation mean and standard deviation score in both stable and unstable extravert groups.

\begin{tabular}{lllll}
\hline \multirow{2}{*}{ Statistical observations } & Mean & & Standard of deviation & Stable extrovert \\
\cline { 2 - 5 } & Unstable extrovert & Stable extrovert & Unstable extrovert & $4 / 37$ \\
\hline Receiving & $29 / 86$ & $33 / 67$ & $4 / 62$ & $5 / 33$ \\
Evaluation & $29 / 43$ & $28 / 56$ & $3 / 54$ & $3 / 37$ \\
Trigger & $30 / 58$ & $33 / 21$ & $4 / 57$ & $4 / 96$ \\
Search & $33 / 73$ & $35 / 93$ & $5 / 73$ & $8 / 59$ \\
Planning & $29 / 01$ & $33 / 86$ & $3 / 99$ & $5 / 52$ \\
Implementation & $30 / 58$ & $34 / 76$ & $4 / 58$ & $3 / 32$ \\
Assessment & $30 / 63$ & $32 / 36$ & $3 / 60$ & $20 / 71$ \\
Total score & $313 / 85$ & $239 / 32$ & $21 / 21$ & \\
\hline
\end{tabular}

Table 1 shows the descriptive statistics for each of the strategies of self-regulation and total score of self-regulation in two groups of stable extrovert and unstable extroverts. In the unstable extrovert group, the highest obtained mean related to investigation strategy was $(\mathrm{M}=33 / 7)$ and lowest mean related to planning strategy was $(M=29$. Also in stable extrovert group, the highest mean for investigation strategy was $(\mathrm{M}=35 / 9)$ and the lowest mean related evaluation strategy $(M=28 / 5)$.

Results of t-test to determine significant differences between self-regulation strategies in both groups with stable and unstable extrovert personality were as follows.

- Athletes of stable extrovert group $(\mathrm{M}=33.6, \mathrm{SE}=4.3)$ have used receiving strategy significantly higher than athletes of unstable extrovert group $(\mathrm{M}=29.8, \mathrm{SE}=$ 4.6) $(\mathrm{t}(104)=-4.3, \mathrm{p}<.05, \mathrm{r}=.38)$.

- No significant difference was found between athletes of stable extrovert group $(\mathrm{M}=28.5, \mathrm{SE}=5.3)$ and athletes of unstable extrovert group $(\mathrm{M}=29.4, \mathrm{SE}=3.5)$ in using evaluation strategy $(\mathrm{t}(104)=1.004, \mathrm{p}<.05, \mathrm{r}$ $=.097$ ).

- Athletes of stable extrovert group $(\mathrm{M}=33.2, \mathrm{SE}=3.3)$ have used trigger strategy significantly higher than athletes of unstable extrovert group $(\mathrm{M}=30.5, \mathrm{SE}=$ 4.5) $(\mathrm{t}(104)=-3.2, \mathrm{p}<.05, \mathrm{r}=.3)$.

- Athletes of stable extrovert group $(\mathrm{M}=35.9, \mathrm{SE}=4.9)$ have used investigation strategy significantly higher than athletes of unstable extrovert group $(\mathrm{M}=33.7, \mathrm{SE}$ $=5.7)(\mathrm{t}(104)=-2.07, \mathrm{p}<.05, \mathrm{r}=198)$.

- Athletes of stable extrovert group $(\mathrm{M}=33.6, \mathrm{SE}=4.3)$ have used planning strategy significantly higher than athletes of unstable extrovert group $(\mathrm{M}=29, \mathrm{SE}=3.9)$ $(\mathrm{t}(104)=-3.86, \mathrm{p}<.05, \mathrm{r}=.35)$.

- Athletes of stable extrovert group $(\mathrm{M}=34.7, \mathrm{SE}=5.5)$ have used implementation strategy significantly higher than athletes of unstable extrovert group $(\mathrm{M}=30.5$, SE $=4.5)(\mathrm{t}(104)=-4.25, \mathrm{p}<.05, \mathrm{r}=.384)$.

- Athletes of stable extrovert group $(\mathrm{M}=32.3, \mathrm{SE}=3.3)$ have used assessment strategy significantly higher than athletes of unstable extrovert group $(\mathrm{M}=30.6, \mathrm{SE}=$ 3.6) $(\mathrm{t}(104)=-2.54, \mathrm{p}<.05, \mathrm{r}=.241)$.

Generally, comparison of total score of self-regulation indicated that athletes of stable extrovert group $(\mathrm{M}=33.1$, $\mathrm{SE}=6.8)$ use self-regulation strategy significantly higher than athletes of unstable extrovert group $(\mathrm{M}=30.5, \mathrm{SE}=$ 6.6) $(\mathrm{t}(104)=-4.5, \mathrm{p}<.05, \mathrm{r}=.404)$.

Table 2. The results of t test for self-regulation strategies.

\begin{tabular}{lllll}
\hline \multirow{2}{*}{ Strategies } & \multicolumn{2}{l}{ Statistical observation } & sig & Size Effective (SE) \\
\cline { 2 - 5 } & df & t & $0 / 000$ & $0 / 387$ \\
\hline Receiving & 104 & $-4 / 3$ & $0 / 318$ & $0 / 097$ \\
Evaluation & 104 & $1 / 004$ & $0 / 001$ & $0 / 305$ \\
Trigger & 104 & $-3 / 27$ & $0 / 041$ & $0 / 198$ \\
Search & 104 & $-2 / 07$ & $0 / 000$ & $0 / 353$ \\
Planning & 104 & $-3 / 86$ & $0 / 000$ & $0 / 384$ \\
Implementation & 104 & $-4 / 25$ & $0 / 013$ & $0 / 241$ \\
Assessment & 104 & $-2 / 54$ & $0 / 000$ & $0 / 404$ \\
Total score & 104 & $-4 / 5$ & & \\
\hline
\end{tabular}

\section{Discussion}

Assessing and identifying the factors that can contribute to the success of athletes in sport psychology is an important issue these days. Factors such as self-regulation and personality have been interested by many researchers in the field (Magars, Philips and Hosie, 2008; Hoyt et al., 2009). In order to investigate and identify the factors, this study was aimed to investigate and compare the self-regulation strategies in the Premier League's basketball players of Iran, based on their personality types. After collecting and analyzing data, it was found that many of the samples of the study have extrovert personality and only a few of them (12 persons) had introvert personality. Based on obtained results, it may be concluded that the majority of Iran's Premier League basketball players are extroverts. This finding is consistent with the findings of study conducted by Eagleton 
et al (2007). They found that team sports athletes are highly extroverted.

On other hand, Egan and Stelmack (2003) conducted a study based on Eysenck three-factor model. Their study indicated that athletes have lower mental neurosis and higher extroversion than non-athletes. As team sport such as basketball requires factors such as high mobility, high order to coordinate the tactics of the team, probably these people learn extroversion features.

In addition, the results showed that two groups of stable extroverts and unstable extroverts are significant different in total self-regulation score so that stable extroverts have higher self-regulation than unstable extroverts. Given features of these personality types stated by Eysenck (1991), it may be concluded that stable extroverts have obtained higher scores in the receiving information stage since they have sociability, and vitality features that these group of people will make higher effort to achieve needed skills and capacity of people. In this line, Toering (2009) stated that high scores in self-regulation are correlated with better performance in athletes. On the other hand, unstable extroverts have features such as irritability, aggressiveness, irritability and restlessness (Eysenck, 1991). Due to these features, they face with problems in of self-regulation obtain lower scores in this regard. In the component of receiving information, they obtained lower scores. Due to the lack of ability to learn enough information based on the results of Miller and Brown (1999), they learn less skills and techniques.

Considering studies that have been done in this regard, self-regulation skill is one of the most important predictor of significant impact on achievement of people to difficult and complex tasks (Magar, Philips and Hosie, 2008; Barkhof, Pagano and Hibi, 2007). The results of study showed that the type of personality can be an important factor in determining the capacity to receive information about the tasks. Without doubt, people who have a greater capacity in this regard, they make higher attempts to gain necessary skills and techniques. Also during the competition, these people can easily understand the opponent's weaknesses and attack him cleverly with proper plans. Moreover, in difficult times for excitement, interaction and cooperation with each other in abilities, because this step shows information learning performance in different environments, which can have a

example when fans make a loud voice, people with high selfregulation can identify the coach's instructions and produce better results through using these instructions.

In addition, it can be easily understood that self-regulation leads people toward proper selection of exercise or training, increased training intensity, and performance development based on the competitive conditions (Barkhof, Pagano and Hibi, 2007; Stadler, Oettingen, 2009). Also, use of this model Miller and Brown model) in sport indicates that that people with low self-regulation hardly resist against temporary pleasures and temptations that are the obstacles to regular exercise. They scarify their long-term goals to temporary pleasures. As a result, in the critical moments of competition when athletes are in urgent need of operational goals, selfregulation skills can interpose to control factors such as arousal level, performance prediction, and focus and attention (Hedger, 2010).

Furthermore, it is obvious that adherence to goals despite the obstacles and successful attachment to trainings are a function of self-regulation (Hagger et al, 2010). Selfregulation deficiency gives an explanation to why some athletes give up or quit training. Hence, higher selfregulation ability helps athletes to reach their goals by a firm intention to confront the barriers.

\section{Conclusion}

In sum, considering the results of the study, it can be realized that that the Iranian basketball players have extrovert personalities. On other hand, given the classification of personality types by Eysenck, they fall into two groups of stable extrovert and unstable extrovert that each of these groups has special self-regulation scores. Stable extroverts have higher self-regulation that helps them receive information about their work and increased performance as a result. However, people who are unstable extrovert would probably face with difficulty in learning skills and this would reduce their performance. In addition, as mentioned before, self-regulation skill can lead into better learning of sport skills that it requires to learn self-regulation skills that must be presented by experts.

\section{Appendix}

Table A1. Self-regulation mean and standard deviation score in both stable and unstable extravert.

\begin{tabular}{lllll}
\hline \multirow{2}{*}{ Statistical observations } & Mean & \multicolumn{3}{l}{ Standard of deviation } \\
\cline { 2 - 5 } & Unstable extrovert & Stable extrovert & Unstable extrovert & Stable extrovert \\
\hline Receiving & $29 / 86$ & $33 / 67$ & $4 / 62$ & $4 / 37$ \\
Evaluation & $29 / 43$ & $28 / 56$ & $3 / 54$ & $5 / 33$ \\
Trigger & $30 / 58$ & $33 / 21$ & $4 / 57$ & $3 / 37$ \\
Search & $33 / 73$ & $35 / 93$ & $5 / 73$ & $4 / 96$ \\
Planning & $29 / 01$ & $33 / 86$ & $3 / 99$ & $8 / 59$ \\
Implementation & $30 / 58$ & $34 / 76$ & $4 / 58$ & $5 / 52$ \\
Assessment & $30 / 63$ & $32 / 36$ & $3 / 60$ & $3 / 32$ \\
Total score & $313 / 85$ & $239 / 32$ & $21 / 21$ & $20 / 71$ \\
\hline
\end{tabular}


Table A2. The results of t test for self-regulation strategies.

\begin{tabular}{|c|c|c|c|c|}
\hline \multirow{2}{*}{ Strategies } & \multicolumn{4}{|c|}{ Statistical Observations } \\
\hline & df & $\mathbf{t}$ & sig & Size Effective (SE) \\
\hline Receiving & 104 & $-4 / 3$ & $0 / 000$ & $0 / 387$ \\
\hline Evaluation & 104 & $1 / 004$ & $0 / 318$ & 0/097 \\
\hline Trigger & 104 & $-3 / 27$ & $0 / 001$ & $0 / 305$ \\
\hline Search & 104 & $-2 / 07$ & $0 / 041$ & $0 / 198$ \\
\hline Planning & 104 & $-3 / 86$ & $0 / 000$ & $0 / 353$ \\
\hline Implementation & 104 & $-4 / 25$ & $0 / 000$ & $0 / 384$ \\
\hline Total score & 104 & $-4 / 5$ & $0 / 000$ & $0 / 404$ \\
\hline
\end{tabular}

- Unstable Extroverts = Stable Extrovert

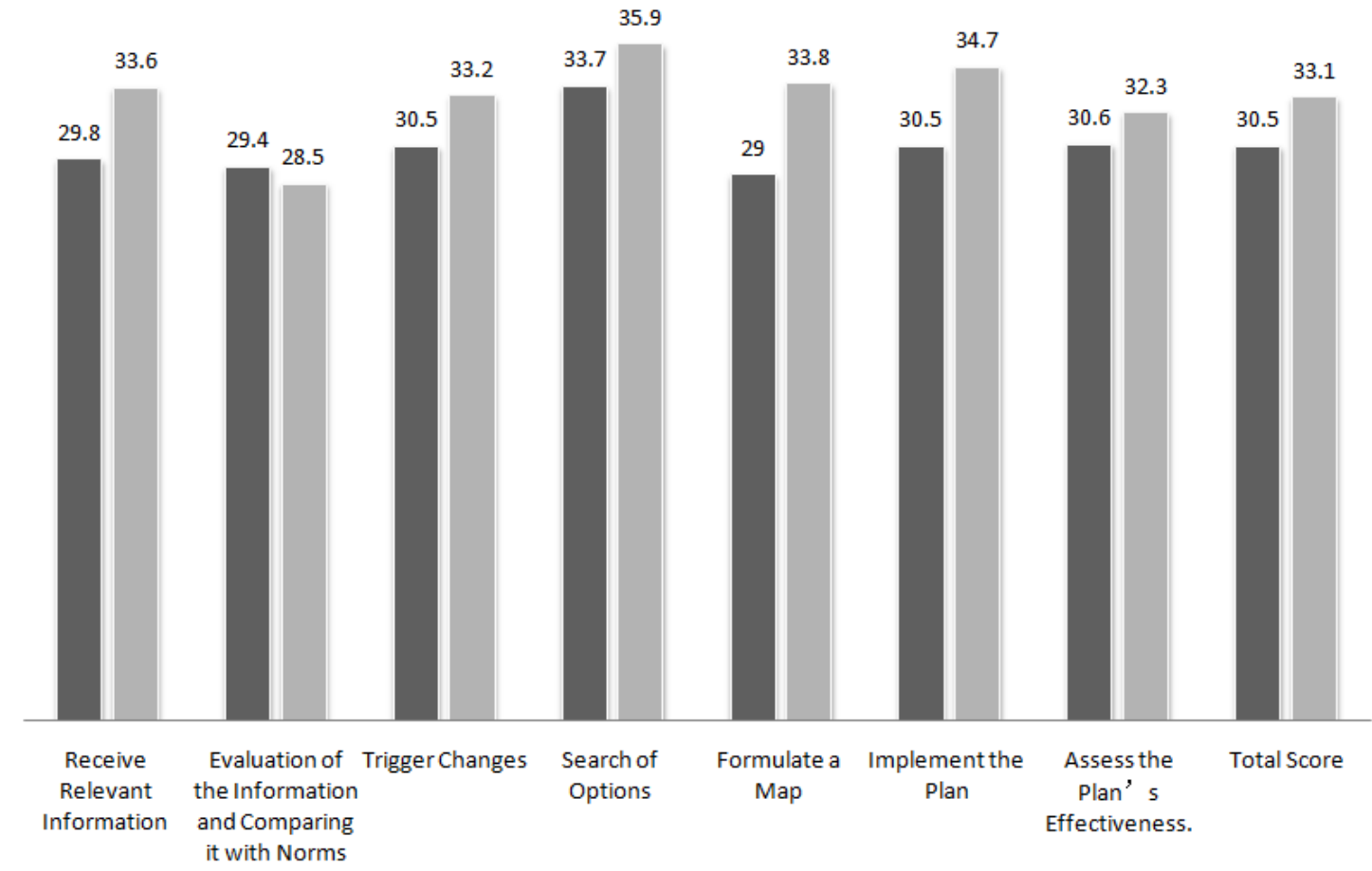

Figure A1. comparison of scores mean of self-regulation strategies of athletes who have extrovert personality and unstable personality.

\section{References}

[1] Allport, G, W. (1937). Personality: A psychological interpretation. New York: Holt, Rinehart \& Winston, Inc.

[2] Banfield, J. F., Wyland, C. L., Macrae, C. N., Munte, T. F., \& Heatherton, T. F. (2004). The Cognitive Neuroscience of Selfregulation. In R. F. Baumeister, \& K. D. Vohs (Eds.), Handbook of self-regulation: research, theory, and applications (pp. 62-83). New York: The Guilford Press.

[3] Barkhoff, H., Pagano, I., \& Heiby, E. (2007). Self-regulation Skills of a Competitor Type vs. a Training Champion Athlete in Artistic Roller Skating: Longitudinal Analyses of Mood in Highlight Sport Competitions. Journal of the American Board of Sport Psychology, 1, 1-14.

[4] Brown, J. M., Miller, W. R., \& Lawendowski, L. A. (1999). The self-regulation questionnaire. In Vande Creek, L. \& Jackson, T. L. (Eds.), Innovations in clinical practice: $A$ source book. Sarasota, FL: Professional Resource Press/Professional Resource Exchange.
[5] Dadsetan, P. (2004). Criminal Psychology. Tehran: Leyli.

[6] Dehghan, M. (2011). Capital development in moral identity: Role of Mediation of Self-regulation. Iran, Tehran: Tehran University.

[7] Eagleton, J. D., Mckelvie, S. J., \& de Man, A. (2007). Extraversion and neuroticism in team sport participants, individual sport participants, and nonparticipants. Bishop's University, Sherbrooke, Québec, Canada.

[8] Egan, S., \& Stelmack, R. M. (2003). A personality profile of Mount Everest climbers. Personality and Individual Differences, 34, 1491-1494.

[9] Eysenck, H. J. (1947). Dimensions of personality. London: K. Paul, Trench, Trubner.

[10] Eysenck, H. J., \& Eysenck, S. B. G. (1975). Manual of the Eysenck personality questionnaire. London: Hodder \& Stoughton.

[11] Eysnck, S. B. G., Eysenck, H. J., \& Barret, P. (1985). A Revised Version of the Psychoticism Scale. Personality and Individual Differences, 6, 21-29. 
[12] Eysenck, H. J., \& Eysenck, M. W. (1985). Personality and individual differences: A natural science approach. New York: Plenum Press. Personality and individual differences: A natural science approach. New York: Plenum Press.

[13] Eysenck, H. J., \& Eysenck, S. B. G. (1991). Manual of Eysenck Personality Scales (ESP Adult). London; Hodder \& Stoughton.

[14] Feist, J., Feist, G. (2004). Theories of Personality. (YMohammadi, Trans.). Tehran: Ravan.

[15] Gill, Diane. L. (2000). Psychological dynamics of sport and exercise. Champaign, United State: Human Kinetics.

[16] Hagger, M. S., Wood, C. W., Stiff, C., \& Chatzisarantis, N. L. D. (2010). Self-regulation and self-control in exercise: the strength-energy model. International Review of Sportand Exercise Psychology, (3) 1, 62-86.

[17] Hoyt, A. L., Rhodes, R. E., Hausenblas, H. A., \& Giacobbi, P. R. (2009). Integrating Five Factor Model Facet Level Traits with the Theory of Planned Behavior and Exercise. Psychology of Sport and Exercise, 10, 565-572.

[18] Kanfer, F. H. (1970). Self-regulation: Research, issues, and speculation. In C, Neuringer, \& J, L, Michael (Eds.), Behavior modification in clinical psychology (pp. 178- 220). New York: Appleton-Century-Crofts.

[19] Lazarus, R. S., \& Monat, A. (1979). Personality (3rd ed.). Englewood Cliffs, NJ: Prentice Hall.

[20] Magar, E. C. E., Phillips, L. H., \& Hosie, J. A. (2008). Selfregulation and Risk-taking. Personality and Individual Differences, 45, 153-159.

[21] Neal, D. J., \& Carey, K. B. (2005). A follow-up psychometric analysis of the self-regulation questionnaire. Psychology of Addict Behavior, 19(4), 414-422.
[22] Rafieiniya, P., Azad Falah, P., Fathiashtiyani, A.,\&Tabatabayi, K. (2006). The Role of Extraversion, Neuroticism and Positive and Negative Mood on Emotional Information Processing. Scientific Research Journal of Tabriz University, 2, 129.

[23] Stadler, G., Oettingen, G., \& Gollwitzer, P.M. (2009). Physical activity in women effects of a self-regulation intervention. American Journal of Preventive Medicine, 31, 29-34.

[24] Toering, T. T., Elferink-Gemser, M. T., Jordet, G., \& Visscher, C. (2009). Self-regulation and Performance Level of Elite and Non-elite Youth Soccer Players. Journal of Sports Sciences, 27, 1509-1517.

[25] Zimmerman, B. J. (1986). Development of self-regulated learning. Which are the key sub processes? Contemporary Educational Psychology, 16, 307-313.

[26] Zimmerman, B. J. (1989b). A social cognitive view of selfregulated academic learning. Journal of Educational Psychology, 81, 329-339.

[27] Zimmerman, B. J. (1999). Attaining self-regulation: A socialcognitive perspective. In M. Boekaerts, P. Pintrich, \& M. Seidner (Eds), Self-regulation: Theory, research, and applications. Orlando, FL: Academic Press.

[28] Zimmerman, B. J. (2006). Development and Adaptation of Expertise: The Role of Self-regulatory Processes and Beliefs. In K. A. Ericsson, N. Charness, P., Feltovich, J., \& Hoffman, R. R (Eds.), The Cambridge Handbook of Expertise and Expert Performance, (pp. 705-722). New York, NY: Cambridge University Press. 